\title{
Antiviral mechanism of polyanionic carbosilane dendrimers against HIV-I
}

This article was published in the following Dove Press journal:

International Journal of Nanomedicine

5 April 2016

Number of times this article has been viewed

\section{Enrique Vacas-Córdoba ${ }^{1-4}$ \\ Marek Maly ${ }^{5,6}$ \\ Francisco J De la Mata ${ }^{4,7}$ \\ Rafael Gómez ${ }^{4,7}$ \\ Marjorie Pion ${ }^{1-4}$ \\ $M^{a}$ Ángeles Muñoz- \\ Fernández ${ }^{1-4}$}

'Molecular Immunobiology

Laboratory, General Universitary

Hospital Gregorio Marañon, ${ }^{2}$ Health

Research Institute Gregorio Marañon,

${ }^{3}$ Spanish HIV HGM BioBanK,

${ }^{4}$ Networking Research Center on Bioengineering, Biomaterials and Nanomedicine (CIBER-BBN), Madrid, Spain; ${ }^{5}$ Faculty of Science, Jan Evangelista Purkyně University, Ústí nad Labem, Czech Republic; ${ }^{6}$ Laboratory of Applied Mathematics and Physics (LaMFI), University of Applied Sciences and Arts of Southern Switzerland, Manno, Switzerland;

${ }^{7}$ Dendrimers for Biomedical Applications Group (BiolnDen), University of Alcalá, Alcalá de

Henares, Madrid, Spain
Correspondence: $M^{\mathrm{a}}$ Ángeles MuñozFernández

Molecular Immunobiology Laboratory, General Universitary Hospital,

Gregorio Marañón, C/Doctor

Esquerdo 46, 28007 Madrid, Spain

$\mathrm{Tel}+34915868565$

Fax +34 91 5868018

Email mmunoz.hgugm@gmail.com

\begin{abstract}
Nanotechnology-derived platforms, such as dendrimers, are very attractive in several biological applications. In the case of human immunodeficiency virus (HIV) infection, polyanionic carbosilane dendrimers have shown great potential as antiviral agents in the development of novel microbicides to prevent the sexual transmission of HIV-1. In this work, we studied the mechanism of two sulfated and naphthylsulfonated functionalized carbosilane dendrimers, G3-S16 and G2-NF16. They are able to inhibit viral infection at fusion and thus at the entry step. Both compounds impede the binding of viral particles to target cell surface and membrane fusion through the blockage of gp120-CD4 interaction. In addition, and for the first time, we demonstrate that dendrimers can inhibit cell-to-cell HIV transmission and difficult infectious synapse formation. Thus, carbosilane dendrimers' mode of action is a multifactorial process targeting several proteins from viral envelope and from host cells that could block HIV infection at different stages during the first step of infection.
\end{abstract}

Keywords: carbosilane dendrimer, HIV, mechanism, microbicide, nanotechnology

\section{Introduction}

Although new human immunodeficiency virus (HIV) infections have reduced by $35 \%$ since 2000, $\sim 2$ million (1.9-2.2 million) of newly infected people and 1.2 million acquired immune deficiency syndrome (AIDS)-related deaths are still occurring worldwide. ${ }^{1}$ HIV sexual transmission is responsible for $>80 \%$ of new infections around the world and continues to be one of the most difficult manageable routes of transmission. ${ }^{2}$ Different HIV preventive strategies such as preexposure prophylaxis through the use of topical microbicides and the oral administration of antiretroviral drugs (ARV) are being showed as effective methods against the HIV infection. ${ }^{3-6}$ The successful Phase II clinical trial CAPRISA 004 using tenofovir-based gel to prevent male-to-female HIV transmission has shown that ARV can be used as effective topical microbicides. ${ }^{7}$ However, failures in other recent clinical trials indicate that we must keep seeking out new effective compounds that could help us to block worldwide spreading of HIV. ${ }^{8-10}$

In the last few years, nanotechnology offered a huge battery of novel nanoparticles such as dendrimers and macromolecules characterized by hyperbranched, well-defined, monodisperse, three-dimensional structures that are being developed as drug delivery vehicles or as therapeutic agents. ${ }^{11-17}$ The controlled synthesis of dendrimers allows the assembly of highly defined, single molecule structures that radiate out in branches from a central initiator core. The type of core and branching units can be engineered to generate a broad variety of dendrimers with different sizes, shapes, and surface chemical functionalized groups that can provide distinct biological and pharmacological properties. ${ }^{18}$ Unlike small molecule drugs, dendrimers can bind to their target in a multivalent manner due 
to their hyperbranched structure, offering unique opportunities in the synthesis of novel antiviral agents.

Dendrimers containing several types of functionalized groups at their periphery have shown effective anti-HIV activity as nonspecific microbicides. In this way, anionic dendrimers comprising benzyhydryl amide cores and lysine branches, which were functionalized with naphthalene disulfonic acid or 3,5-disulfobenzoic acid groups, exhibited great activity against HIV-1 and herpes simplex virus 2 (HSV-2) infections, preventing viral entry and HIV envelope-mediated cell-to-cell fusion. ${ }^{18,19}$ Moreover, polycationic "viologen"based dendrimers have also shown anti-HIV activity by interaction with the chemokine receptor CXCR $4 .{ }^{20}$ Other dendrimers have presented dual acting mechanism such as four-generation polyamidoamine (PAMAM) branchednaphthalene disulfonic surface groups ended SPL2923 ${ }^{18}$ or polysulfonated dendrimer BRI2923, ${ }^{21}$ which inhibited not only HIV-1 entry but also later steps (reverse transcriptase/ integrase) of the viral replicative cycle. Multivalent dendrimeric compounds containing carbohydrates expressed on immune cells such as globotriose and $3^{\prime}$-sialyl lactose glycosphingolipids also inhibited infection of HIV-1 targeting HIV entry to its target cells, ${ }^{22}$ whereas multivalent glycodendrimeric compounds were shown to prevent HIV transmission via DC-SIGN in dendritic cells (DCs). ${ }^{23}$

A relative recent group of dendrimers with carbosilane structure has also demonstrated its potential as topical microbicides against HIV and other pathogens. ${ }^{12,13,24-29}$ These nanosystems present a C-and $\mathrm{Si}$-based skeleton, and they distinguish from other dendrimers in the high apolarity of their central core and the high mobility of their peripheral branches.

In our work, we researched the antiviral mechanism of two carbosilane dendrimers, G3-S16 and G2-NF16, previously described as potent anti-HIV compounds. ${ }^{24}$

\section{Materials and methods \\ Cell culture}

Peripheral blood mononuclear cells (PBMCs) were isolated by a standard Ficoll-Hypaque density gradient from buffy coats and monocyte-derived dendritic cells (Mo-dDCs) were provided by the Spanish HIV HGM BioBank (Hospital General Universitario Gregorio Marañón) as already described. ${ }^{30}$ HeLa MAGI P4.R5 and TZM.bl cell lines were cultured as described. ${ }^{24,28}$ The Ethical Committee of Clinical Research of the Health Institute of Gregorio Maranon Hospital deemed that no approval was required for this set of experiments because the experiments were performed on commercially available cell lines. RajiDC-SIGN, a B lymphoblastic cell line expressing high levels of DC-SIGN surface marker, ${ }^{31} 8 \mathrm{E} 5 / \mathrm{LAV}$, containing a single integrated copy of proviral DNA, ${ }^{32}$ and Jurkat E6-1 cell lines were cultured in RPMI complete medium (Thermo Fisher Scientific, Waltham, MA, USA) supplemented with 5\% fetal bovine serum. All cell lines are from NIH AIDS Research and Reference Reagent Program, Germantown, MD, USA.

Cryopreserved PBMC samples and associated data were provided by the Spanish HIV HGM BioBank.

\section{Virus strains}

Virus stock of R5-HIV-1 ${ }_{\mathrm{NL}(\mathrm{AD} 8)}$ and X4-HIV-1 ${ }_{\mathrm{NL} 4.3}$ tropic strains were produced as described. ${ }^{24}$ Env-X4-luc and env-VSV-G (vesicular stomatitis virus glycoprotein)-luc HIV lentivectors were produced by transient cotransfection of pNL4-3.Luc. $\mathrm{R}^{-}$. $\mathrm{E}^{-}$with plasmid expressing HIV-X4 envelope ( $\mathrm{pHXB} 2-$ env, NIH AIDS Research and Reference Reagent Program) or expressing VSV-G envelope (Addgene, Cambridge, MA, USA) in 293T cell line. Both lentivectors contain luciferase gene under the control of HIV promoter. Infectious and physical titers of viral stock were evaluated as described. ${ }^{33}$

\section{Dendrimers and reagents}

Polyanionic carbosilane dendrimers, third-generation G3-S16 with 16 sulfated end groups $\left(\mathrm{C}_{256} \mathrm{H}_{508} \mathrm{~N}_{48} \mathrm{Na}_{16} \mathrm{O}_{64} \mathrm{~S}_{16} \mathrm{Si}_{29}\right.$; $\mathrm{MW}$ : $6,978.41 \mathrm{~g} / \mathrm{mol}$ ) and second-generation G2-NF16 with naphthylsulfonated end groups $\left(\mathrm{C}_{184} \mathrm{H}_{244} \mathrm{~N}_{24} \mathrm{Na}_{16} \mathrm{O}_{56} \mathrm{~S}_{16} \mathrm{Si}_{13}\right.$; MW: 4,934.02 $\mathrm{g} / \mathrm{mol}$ ), were prepared according to reported methods. ${ }^{34}$ Several reagents and ARV were used as controls: zidovudine (AZT; GSK, GlaxoSmithKline plc, London, UK), enfuvirtide (T-20; Hoffman-La Roche Ltd., Basel, Switzerland), atazanavir (ATV; Bristol-Myers Squibb, New York, NY, USA), and raltegravir (RAL; Merck Millipore, Billerica, MA, USA); Suramin, a polyanionic compound that could mimic the function of dendrimers; CXCR4 chemokine receptor antagonist AMD3100, CCR5 receptor antagonist TAK779 , and colchicine, a microtubule polymerization inhibitor (all from Sigma-Aldrich Co., St Louis, MO, USA).

\section{Time-of-addition experiment}

TZM.bl cells were infected with X4-HIV- ${ }_{\mathrm{NL} 4.3}$, and antiviral compounds were added at different times ( -1 hour, 0 hour, 1 hour, 2 hours, ..., 7 hours) pre and post infection. Viral infection was quantified 30 hours post infection by measuring luciferase expression (Luciferase Assay System; Promega Corporation, Fitchburg, WI, USA).

\section{Inhibition of HIV binding}

Activated PBMCs were pretreated for 1 hour with a range of dendrimer concentrations. Then, cells were infected during 3 hours with $100 \mathrm{ng} / 10^{6}$ cells of X4-HIV- $1_{\mathrm{NL} 4.3}$ or R5-HIV-1 $1_{\mathrm{NL}(\mathrm{AD} 8)}$ corresponding to an average of multiplicity 
of infection of 0.1 at $4^{\circ} \mathrm{C}$. HIV p24 antigen was then quantified by Ag p24 gag enzyme-linked immunosorbent assay (ELISA) kit from cell lysates (INNOTEST HIV-Antigen mAb; Innogenetics, Fujirebio Europe NV, Belgium).

\section{HIV viral inactivation by dendrimers}

Four nanograms of X4-HIV-1 ${ }_{\mathrm{NL} 4.3}$ or R5-HIV-1 ${ }_{\mathrm{NL}(\mathrm{AD} 8)}$ were attached on poly-L-lysine (Sigma-Aldrich Co.)-coated plates by centrifugation at 3,200 rpm for 1 hour. Attached HIV particles were treated with compounds for 1 hour and then extensively washed to remove unbound dendrimer. A total of $2 \times 10^{5}$ activated PBMCs were then added into the wells. PBMC supernatants were collected 3 days later, and virus production was quantified by Ag p24 ${ }^{\text {gag }}$ ELISA kit.

\section{Inhibition of HIV replication}

Activated PBMCs were treated with dendrimers for 1 hour and then infected overnight with $50 \mathrm{ng}$ of env-X4-luc and env-VSVG-luc lentivectors. After 2 days of infection, viral infection was quantified measuring luciferase activity.

\section{Cell-based fusion assay}

The protocol used for cell-based fusion assay was already described $^{35}$ with slight modifications. Briefly, 8E5/LAVderived T-cell line that expresses HIV proteins (except retrotranscriptase), notably gp120 at their surface, was cocultured with HeLa MAGI P4.R5 cells that express high level of CD4 at their surface, at 1:1 ratio for 48 hours in the absence or presence of G3-S16, G2-NF16, AZT, and T-20. Upon the membrane fusion, Tat protein from $8 \mathrm{E} 5$ cells is able to activate reporter $\beta$-galactosidase expression in HeLa MAGI P4.R5 cells. The percentage of 8E5-HeLa MAGI membrane cell fusion was calculated with respect to the positive control of untreated cells.

\section{HIV-I gPI 20/CD4 ELISA}

A gp120 capture ELISA (ImmunoDiagnostics Inc., Woburn, MA, USA) was used to test the inhibitory activity of polyanionic carbosilane dendrimers against gp120-CD4 binding. Briefly, recombinant HIV-1IIIB gp120 protein $(100 \mathrm{ng} / \mathrm{mL})$ was preincubated for 20 minutes in the absence or presence of dendrimers and then added to a CD4-coated plate. The amount of captured gp120 was detected by peroxidaseconjugated murine anti-gp $120 \mathrm{mAb}$ in Synergy 4 microplate reader (BioTek Instruments, Winooski, VT, USA).

\section{Determination of cellular surface markers-dendrimers interaction}

Activated PBMCs were treated with dendrimers for 15 minutes at $4^{\circ} \mathrm{C}$ and then labeled with anti-CD4-PC7 (13B8.2 clone;
Beckman Coulter, Fullerton, CA, USA), anti-CXCR4-APC (12G5 clone; BD Biosciences, San Jose, CA, USA), or antiCCR5-PE (2D7 clone; BD Biosciences). Levels of CD4, CXCR4, and CCR5 at the cellular surface were followed by flow cytometry (Gallios; Beckman Coulter) and analyzed by FlowJo Software (Tree Star, Inc., Ashland, OR, USA). Integrated mean fluorescence intensity $(\mathrm{iMFI})=\%$ of positive cells $\times$ MFI of surface marker.

\section{Cell-to-cell HIV transmission experiments}

The ability of dendrimers to impede the transfer of viral particles from infected donor cells to target cells was determined by coculturing Raji-DC-SIGN or Mo-dDC HIV-pulsed cells (from three different donors) with TZM. bl cells. Briefly, Raji-DC-SIGN or Mo-dDCs were pulsed for 2 hours with X4-HIV-1 ${ }_{\mathrm{NL} 4.3}$ or R5-HIV-1 ${ }_{\mathrm{NL}(\mathrm{AD} 8)}$ and then extensively washed to eliminate the noninternalized HIV particles. Afterward, cells were cocultured for 5 hours with TZM.bl already pretreated with dendrimers for 1 hour. Viral transfer was determined by measuring luciferase expression levels in TZM.bl cells at 48 hours post infection.

\section{Synapse formation and fluorescence confocal microscopy}

Carboxyfluorescein succinimidyl ester (CFSE)-violet (Thermo Fisher Scientific)-labeled T-cell derived Jurkat cells $\left(3 \times 10^{5}\right.$ cells/condition) were left to adhere on poly-Llysine-treated glass coverslips for 2 hours at $37^{\circ} \mathrm{C}$. On the other hand, mature DCs ( $10^{5}$ cells/condition) were incubated with X4-HIV- $1_{\text {NL4.3 }}$ at multiplicity of infection $=1$ for 4 hours at $37^{\circ} \mathrm{C}$ and treated with compounds for 1 hour before adhesion at $37^{\circ} \mathrm{C}$ on the coverslips for 1.5 hours to allow contact with Jurkat cells. In parallel, Jurkat attached cells were treated with dendrimers for 1 hour and then cocultured with nontreated (NT) HIV-infected DCs. Cells were then fixed, permeabilized, and stained with mouse anti-human CD81 primary antibody (BD Biosciences). HIV-1 p24 gag was detected using a monoclonal anti-HIV-1 p24 gag (KC57FITC; Beckman Coulter). All single-section images were then processed using ImageJ software (National Institutes of Health, Bethesda, MD, USA).

\section{Computational details for molecular modeling}

Three-dimensional computer models of dendrimer structures were created using dendrimer builder as implemented in the Materials Studio software (Accelrys Inc., San Diego, CA, 
USA). The restrained electrostatic potential (RESP) technique $^{36}$ was used for the calculation of dendrimer atoms' partial charges. For this charge parametrization, the RESP ESP charge Derive III version 5 (RED-III.5) tools were used. The necessary quantum mechanics (QM) calculations (QM structure minimizations, molecular electrostatic potential $[\mathrm{MEP}]$ calculations) were done using GAMESS. ${ }^{37}$ The default, HF/6-31G*, level of theory was used for all chargerelated QM calculations and the MEP was fitted on Connolly molecular surface. Generalized amber force field (GAFF) was used for parameterization of dendrimers. ${ }^{38}$ Missing force field parameters were fitted by minimizing the differences between QM and force field-based relative energies of properly chosen molecular fragments. QM energies were calculated at MP2/ HF/6-31G** level of theory using GAMESS, and fitting was accomplished using paramfit routine from Amber12 software. ${ }^{39}$ Van der Waals parameters for Si atoms were taken from the MM3 force field. ${ }^{40}$ For simulations of CD4 and gp120, force field ff12SB was used. CD4 and gp120 structures obtained from PDB: $2 \mathrm{~B} 4 \mathrm{C}^{41}$ were preprocessed using $\mathrm{H}++$ routine to ensure correct ionic states in all titratable groups (neutral $\mathrm{pH}$ ) and eventually to add missing atoms. ${ }^{42}$ First, the individual molecules were solvated in explicit water (TIP3P model) with the proper number $\mathrm{Na}^{+}$and $\mathrm{Cl}^{-}$ions to preserve neutrality of the system and to ensure the correct ionic strength $(0.15 \mathrm{M})$. These stand-alone systems were minimized $(5,000$ steps with $2 \mathrm{kcal} /\left(\mathrm{mol} \AA^{2}\right)$ restraint $+5,000$ without restraint $)$, heated (200 ps NVT) to $310 \mathrm{~K}$ and equilibrated using $100 \mathrm{~ns}$ long molecular dynamics simulation (NPT). The first $0.5 \mathrm{~ns}$ with restrained solute. These equilibrated components were used for the initial configurations of protein-dendrimer complexes which were created using UCSF Chimera software. ${ }^{43}$ The same steps as in the case of individual components were done with complexes. The length of the NPT simulation ( $T=310 \mathrm{~K}$ and $P=0.1 \mathrm{MPa}$ ) was $100 \mathrm{~ns}$ in case of bigger complexes containing gp120 and 110 ns in case of CD4dendrimer complexes. Hydrogens were constrained with the SHAKE algorithm to allow 2 fs time step and Langevin thermostat with collision frequency $2 \mathrm{ps}^{-1}$ was used for all MD runs. The pressure relaxation time for weak-coupling barostat was 2 ps. Particle mesh Ewald method (PME) was used to treat long range electrostatic interactions under periodic conditions with a direct space cutoff of 10 Angstroms. The same cutoff was used for van der Waals interactions. The pmemd.cuda module from Amber12 package was used for all the simulation steps described earlier. ${ }^{44}$ The last $10 \mathrm{~ns}$ of the whole simulation were used for energetic analyses (enthalpic contribution $[\mathrm{dH}]$ calculated with 0.1 ns sampling step [ie, 100 frames used], entropic contribution [TdS]) calculated using $1 \mathrm{~ns}$ sampling step (ie, 10 frames used) by using the molecular mechanics/Poisson-Boltzmann surface area (MM/PBSA) methodology + normal mode analysis, as implemented in Amber12 routine MMPBSA.py to obtain estimates of free energies of binding. ${ }^{45}$ PBSA calculations were done using Adaptive Poisson-Boltzmann Solver (APBS) sander from Amber12. The probe radius used for calculation of solvent accessible surface area (SASA) was 1.4 A. Default APBS value $a=0.02508 \mathrm{kcal}^{*} \mathrm{~mol}^{-1 *} \mathrm{~A}^{-2}$ of cavity surfactant parameter for calculation of the non-polar solvent contribution ENPOLAR $=a *$ SASA was used. The dielectric constant of the solute was set to one and, in the case of solvent, to 80 . Normal mode analysis was done, taking in account solvation using HCT Generalized Born implicit solvation model. ${ }^{46}$ The single trajectory approach was used in this study.

\section{Statistical analysis}

All statistical analyses were performed using GraphPad software Prism v.5 (GraphPad Software, Inc., La Jolla, CA, USA). Statistical analysis including the calculation of the mean, standard deviation, standard error of the mean, and $P$-values was performed using Mann-Whitney $U$ nonparametric test. The significance level was set as $P<0.05$.

\section{Results \\ Study of dendrimers' antiviral activity targeting level}

As previously described, polyanionic carbosilane dendrimers G3-S16 and G2-NF16 (Figure S1) have demonstrated high anti-HIV activity in vitro and potential as topical microbicides against HIV-1 infection. ${ }^{24}$ Due to their anionic features, they were proposed as entry inhibitor candidates. However, their specific mode of action remains still unknown. A time-of-addition experiment was performed to determine the stage of the HIV lifecycle where dendrimers are acting (Figure 1A). In comparison with currently used ARV targeting at different steps of viral cycle, both dendrimers were effective only whether they were added in pretreatment or at the first hours post infection indicating their role in the very first step of the HIV infection. Dendrimers showed a total inhibitory capacity of HIV-1 when cells were pretreated 1 hour before infection. Nevertheless, both dendrimers were not able to block the HIV-1 infection when cells were treated 7 hours post infection. Therefore, dendrimers' inhibitory profile was similar to the antiviral profile of T-20, suggesting that they may develop their activity prior to HIV-1 infection or at the entry state.

In order to determine the antiviral mechanism of carbosilane dendrimers, their effect on HIV binding in PBMCs 


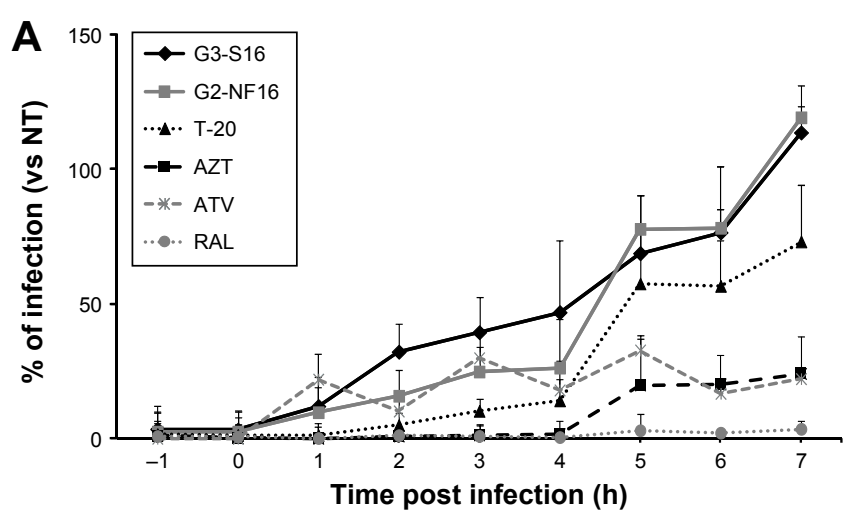

B

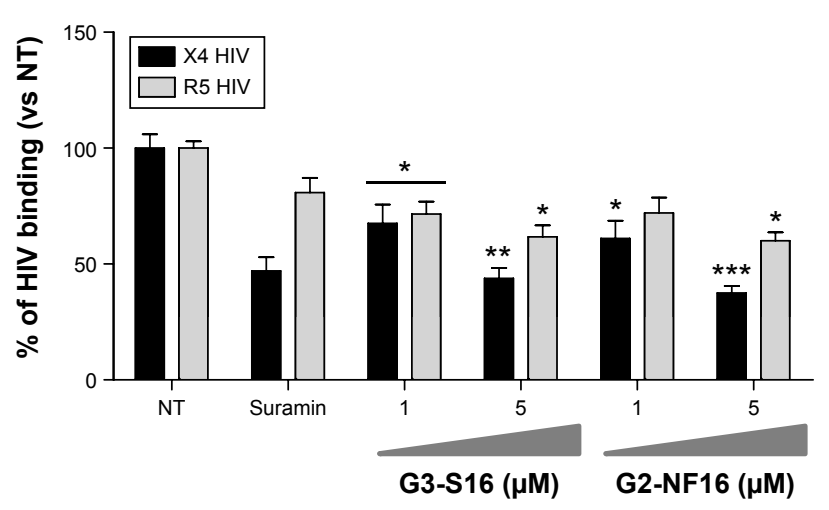

Figure I Time-of-addition and effect of dendrimers on HIV binding experiments.

Notes: (A) Time-of-addition experiment. TZM.bl cells were infected with X4-HIV ${ }_{\mathrm{NL4.3}}$, and tested compounds were added at different times pre and post infection. Viral infection, measured as luciferase activity, was determined. Antiretrovirals targeting different steps in viral cycle, such as T-20 (20 $\mu$ M), AZT (I0 $\mu M$ ), ATV (0.I $\mu$ M), RAL $(\mathrm{I} \mu \mathrm{M})$, and $5 \mu \mathrm{M}$ nontoxic concentration of G3-SI6 and G2-NFI6 dendrimers, were used. Data represent the mean of three independent experiments. (B) Effect of anionic carbosilane dendrimers G3-SI6 and G2-NFI6 on HIV binding in PBMCs. Suramin was used as positive control. $* P<0.05$, $* * P<0.01$, $* * * P<0.00$ I versus control. Data represent the mean \pm SEM of three independent experiments.

Abbreviations: HIV, human immunodeficiency virus; PBMCs, peripheral blood mononuclear cells; SEM, standard error of the mean; NT, nontreated; h, hour; T-20, enfuvirtide; AZT, azidothymidine, zidovudine; ATV, atazanavir; RAL, raltegravir.

was evaluated (Figure 1B). A $5 \mu \mathrm{M}$ concentration of G3-S16 reduced $56 \%$ and $38 \%$ of the binding of X4-HIV- $1_{\mathrm{NL} 4.3}$ and R5-HIV-1 ${ }_{\mathrm{NL}(\mathrm{AD} 8)}$ isolates to the target PBMCs, respectively. On the other hand, at the higher concentration of G2-NF16, $62 \%$ and $40 \%$ reduction of HIV binding was achieved, respectively, for X4-HIV-1 ${ }_{\mathrm{NL} 4.3}$ and $\mathrm{R} 5-\mathrm{HIV}-1_{\mathrm{NL}(\mathrm{AD} 8)}$ isolates in PBMCs in comparison with HIV-1-infected NT PBMCs. It is conceivable that dendrimers acted in part during the binding process, notably in case of X4-HIV- $1_{\text {NL4.3 }}$ isolate but the further complete blockage of HIV-1 replication observed let us assume that an additional block occurs during the first step of HIV-1 infection.

\section{Inhibition of Env/CD4-mediated membrane fusion}

A cell-based fusion assay was performed to mimic the gp120-CD4-mediated fusion process of HIV-1 to the target cell. 8E5 cells, which express HIV-1 Env on their surfaces and Tat protein in their cytoplasms and HeLa-MAGI P4.R5 CD4+ cells, can fuse as the result of the gp120-CD4 interaction. Level of fused cells can be indirectly determined measuring the expression of $\beta$-gal reporter gene. Approximately $70 \%$ of fusion inhibition was observed when $5 \mu \mathrm{M}$ concentrations of G3-S16 and G2-NF16 were added to 8E5-HeLa MAGI CD4+ mixture culture (Figure 2A). Both dendrimers blocked fusion between both cell lines in a dose-dependent manner, supporting the inhibition of HIV binding observed previously.

In addition, to evaluate the specificity of the dendrimers, we studied if differences would be found when PBMCs were treated with dendrimers and then infected with env-X4-luc or env-VSV-G-luc-HIV particles. Both dendrimers were not effective inhibiting env-VSV-G-luc HIV infection, suggesting an HIV-specific activity dependent on the characteristics of viral envelope (Figure S2).

\section{Dendrimers interfere with gp I20-CD4 interaction}

Since the inhibition of cell-cell fusion observed suggests that dendrimers may directly impede the union between gp120 and receptor or coreceptor, the inhibitory activity of G3-S16 and G2-NF16 dendrimers against the gp120-CD4 interaction was also investigated in a competitive gp120-capture ELISA. Compared with the untreated gp120, reductions of $88 \%$ and $92 \%$ of gp 120 bound to CD4-coated plates were found when gp120 was pretreated with $5 \mu \mathrm{M}$ concentration of G3-S16 and G2-NF16 dendrimers, respectively (Figure 2B). A decrease of gp120 bound to CD4-coated plates was not found when protein was treated with T-20 (which binds to gp41 envelope protein). The gp120-capture ELISA data, combined with the results of the cell-based fusion assay, support the hypothesis that the polyanionic carbosilane dendrimers G3-S16 and G2-NF16 inhibit HIV-1 infection by blocking the viral entry, particularly the gp120-CD4 interaction.

\section{Dendrimers bind to viral envelope proteins such as gp 120}

Once we determined that dendrimers carry out their function at attachment, fusion, and entry steps, we researched if they could perform their activity at viral level (Figure 3 ). Viral particles were bonded on plastic plate, treated with dendrimers and 


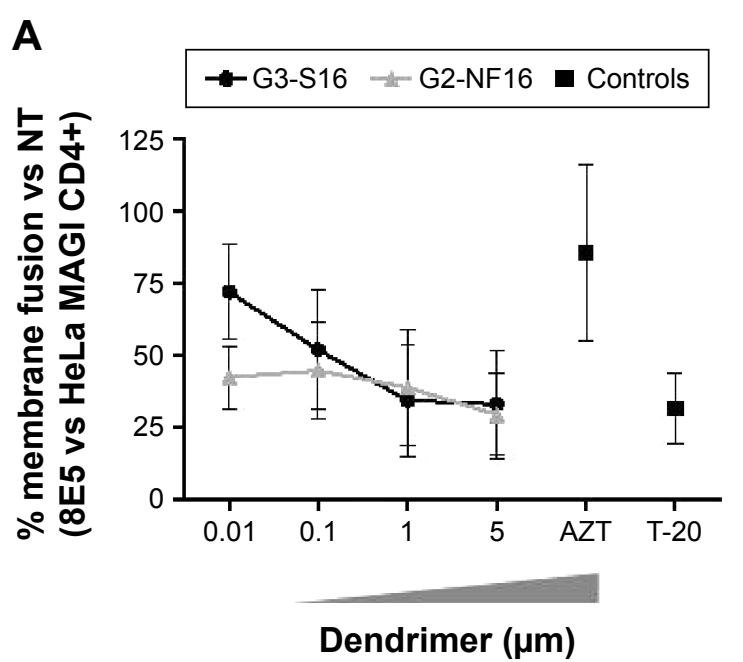

B

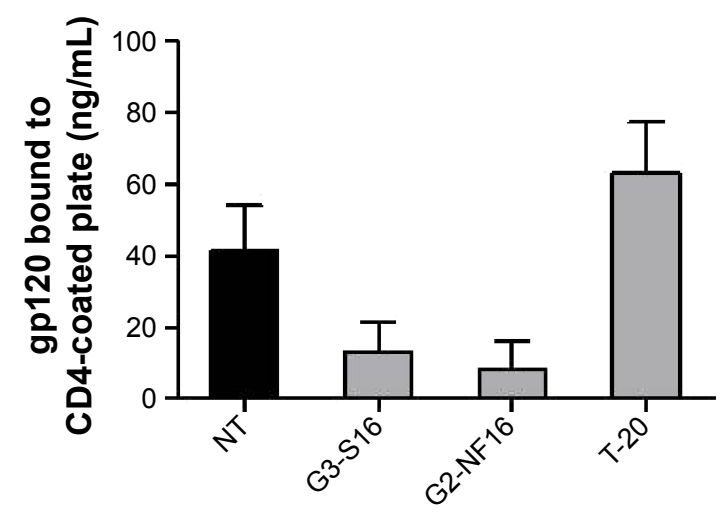

Figure 2 Inhibition of the gpl20-CD4 interaction.

Notes: (A) A cell-based fusion assay was used to mimic the gPl20-CD4-mediated fusion of the viral and host cell membranes. 8E5 and HeLa MAGI P4.R2 CD4+ cells were incubated with a range concentration of carbosilane dendrimers or control antiretrovirals. The percentage of $8 \mathrm{E} 5$-HeLa MAGI membrane cell fusion was calculated as $\beta$-gal activity. This experiment was performed in triplicate, and data points represent the mean \pm SD of three independent experiments. (B) The level of gPl20-CD4 binding inhibition was assessed with a gPI20-CD4 ELISA in the presence or absence of polyanionic carbosilane dendrimers. The assay was done in triplicate; bars represent the mean \pm SEM of two independent experiments.

Abbreviations: SD, standard deviation; ELISA, enzyme-linked immunosorbent assay; SEM, standard error of the mean; NT, nontreated.

then cocultured with activated PBMCs. When viral particles were pretreated with dendrimers, a great reduction in HIV-1 infection was achieved (Figure 3A). Around 95\% reductions in HIV-1 infection were obtained when X4-HIV- $1_{\text {NL4.3 }}$ particles were pretreated with both dendrimers. In case of R5-HIV- $1_{\mathrm{NL}(\mathrm{AD} 8)}, 92 \%$ and $85 \%$ decrease in HIV infection was observed when viral particles were treated with G3-S16 and G2-NF16, respectively. The inhibition values were comparable to triton, a control compound which lyses virus. In addition, molecular modeling was performed to analyze the binding of dendrimers to HIV-1 surface proteins. The ability of G3-S16 and G2-NF16 to interact with HIV-1 gp120 was researched (Figure 3B). The primary target site on the gp120 surface is the one between the "Bridging sheet" and V3 loop, but since V3 loop plays a very important role during the gp120-coreceptor binding process, we studied also the ability of dendrimers to bind in V3 base area that might influence V3 availability for the successful gp120-coreceptor binding. The resulting gp120 conformation together with direct comparison with original bound state is shown in Figure S3. Both dendrimers bind to the gp120 at all binding sites mentioned earlier such as the coreceptor binding site or the V3 loop base. G3-S16 and G2-NF16 interacted strongly with gp120 in its coreceptor binding site with estimated binding energies (dG) of $-120.57 \mathrm{kcal} / \mathrm{mol}$ and $-106.93 \mathrm{kcal} / \mathrm{mol}$, respectively (Table 1). The calculated dG of dendrimer-gp120 interaction at V3 loop base was $-94.29 \mathrm{kcal} / \mathrm{mol}$ and $-86.19 \mathrm{kcal} / \mathrm{mol}$ for G3-S16 and G2-NF16, respectively. Estimated dG values suggest in all cases high affinity leading to creation of stable dendrimer-protein complexes. Similar structure and mainly the same number of the main interaction groups $\left(\mathrm{SO}_{3}\right)$ on dendrimer surface are perhaps also the reason of rather comparable results for both dendrimers. Nevertheless, in all binding sites, we can clearly recognize higher affinities in case of dendrimer G3-S16, suggesting that the more flexible structure of G3-S16 with individually attached $\mathrm{SO}_{3}$ terminal groups was an advantage allowing more effective dendrimer-protein interaction. Summarizing, both dendrimers can block and inactivate X4 and R5-HIV-1 strains since they could bind directly on viral proteins such as gp120 at the surface of HIV-1 particles.

\section{Interaction of dendrimers with cellular surface markers}

We also studied if dendrimers act as well at cellular level and could bind to different cellular surface molecules involved in HIV-1 infection such as CD4, CXCR4, or CCR5 in PBMCs. Cells were treated with G3-S16 or G2-NF16, and then the levels of surface markers were followed by flow cytometry. Dendrimers were thought to compete with flow cytometry antibodies for cell surface marker epitopes. When cells were treated with G3-S16 and G2-NF16, 14\% and 59\% of reduction in CD4 iMFI in comparison with NT PBMCs were observed, respectively (Figure 4); $28 \%$ reduction in iMFI of CCR5 surface coreceptor was observed when PBMCs were treated with G2-NF16. However, no differences were found in iMFI of CXCR4 coreceptor after dendrimers treatment. The ability of carbosilane dendrimers to interact with the CD4 

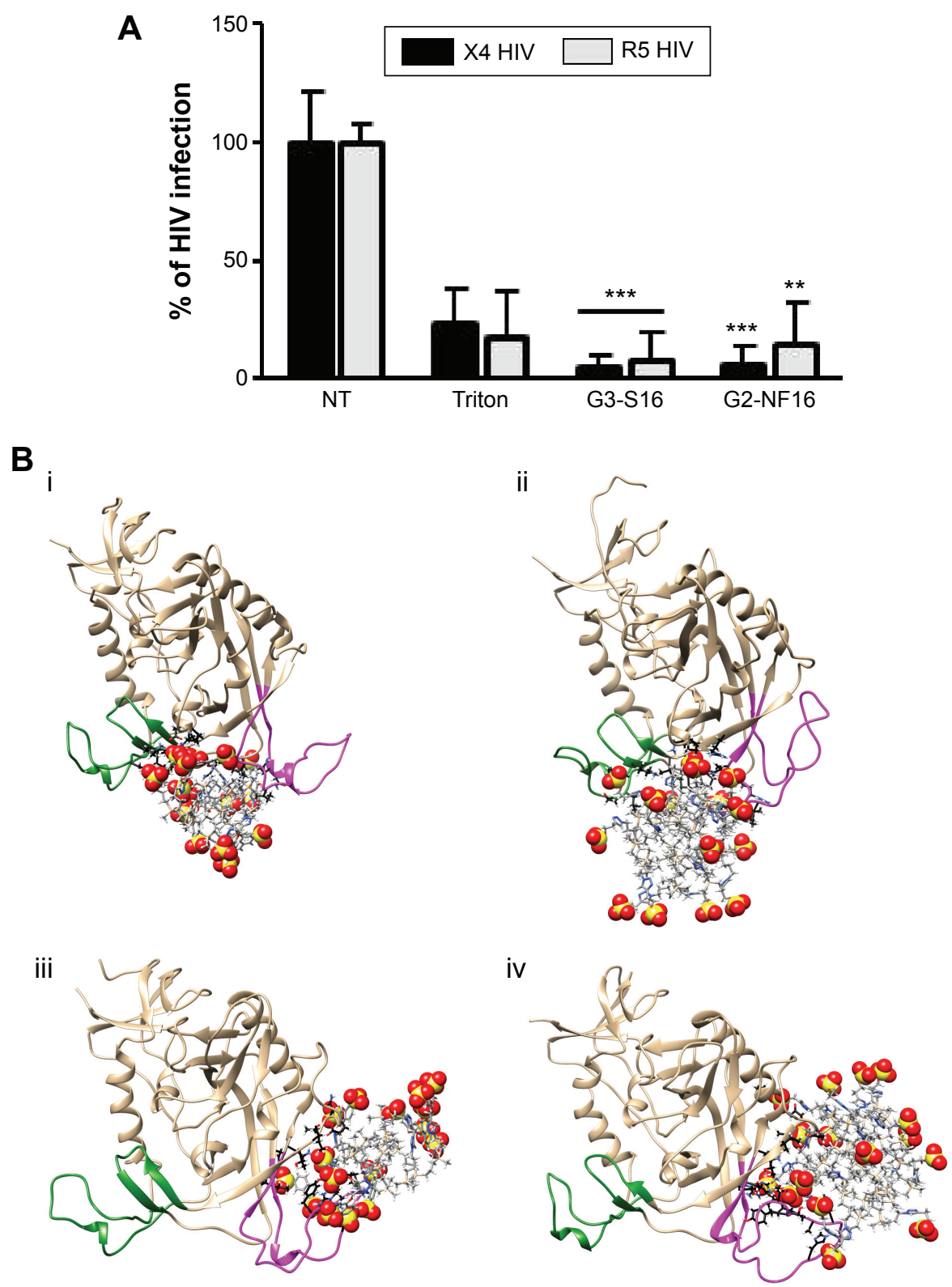

Figure 3 HIV inactivation by G3-SI6 and G2-NFI6.

Notes: (A) HIV particles were treated with $5 \mu \mathrm{M}$ of dendrimers or with Triton X-I00 (I\%) I hour before exposure to activated PBMCs. Antigen P24ag in PBMC supernatants was quantified by ELISA ( $* * P<0.01$, $* * * P<0.001$ vs control). Data represent the mean \pm SD of three independent experiments. (B) Molecular modeling of gpl20-dendrimer complexes. Top - dendrimers bound to gpl20 in the coreceptor binding site (i - gpl20-G2-NFI6, ii - gpl20-G3-SI6). Bottom - dendrimers bound to gpl20 near the V3 loop base (iii - gpl20-G2-NFI6, iv - gpl20-G3-SI6). V3-loop is in magenta; bridging sheet (terminal parts of VI/V2 loops) is in green. Only the closest amino acids to the dendrimer are shown (in ball and stick) using black color for carbons to distinguish them from dendrimer carbons (in gray, stick representation). Colors of the other elements are: $\mathrm{O}$ - red, $\mathrm{S}$ - yellow, $\mathrm{H}$ - white, and $\mathrm{Si}$ - tan. For the dendrimer $\mathrm{SO}_{3}$ groups, the sphere representation is used.

Abbreviations: HIV, human immunodeficiency virus; PBMCs, perpipheral blood mononuclear cells; ELISA, enzyme-linked immunosorbent assay; SD, standard deviation; NT, nontreated.

receptor was also analyzed by computer molecular modeling (Figure S4). Both G3-S16 and G2-NF16 bound to CD4 in a cationic region placed in CD4-gp120 binding interface ( $\mathrm{dG}=-68.29 \mathrm{kcal} / \mathrm{mol}$ and $-51.56 \mathrm{kcal} / \mathrm{mol}$ for G3-S16-CD4 and G2-NF16-CD4 complexes, respectively; Table 1). Summarizing, carbosilane dendrimers interact with different cellular surface proteins such as CD4 or CCR5 involved in the first step of HIV-1 infection such as fusion or entry.

\section{Effect of dendrimers in cell-to-cell HIV-I transmission}

It has been demonstrated that cell-associated virus and not only free virus particles are mainly involved in primary HIV-1 sexual infection. We evaluated the ability of dendrimers to impede the transmission of HIV-1 from X4 or R5-HIV-1-infected donor cells to noninfected target cells. Raji-DC-SIGN cells and primary DCs were used as donor 
Table I MM-PBSA estimates of free energies of binding

\begin{tabular}{|c|c|c|c|c|c|c|}
\hline \multirow[t]{2}{*}{ Energy } & \multicolumn{2}{|l|}{ CD4 } & \multicolumn{2}{|c|}{ gp I 20 coreceptor-binding site } & \multicolumn{2}{|l|}{ gp I 20 V3-root } \\
\hline & G3-S16 & G2-NFI 6 & G3-S16 & G2-NFI6 & G3-S16 & G2-NFI 6 \\
\hline VDW & $-74.90(8.37)$ & $-63.75(5.05)$ & $-113.47(9.63)$ & $-108.87(5.78)$ & $-95.65(7.23)$ & $-90.23(5.72)$ \\
\hline EEL & $-1,236.86(65.58)$ & $-I, 244.52(74.4 I)$ & $-1,319.30(106.70)$ & $-1,599.99(55.13)$ & $-925.62(60.69)$ & $-944.56(61.57)$ \\
\hline EPB & $1,236.66(67.47)$ & $\mathrm{I}, 245.87(74.09)$ & I,308.75 (106.65) & I,591.08 (54.68) & $923.61(61.33)$ & $940.13(62.02)$ \\
\hline ENPOLAR & $-38.16(4.07)$ & $-33.68(1.99)$ & $-56.42(3.43)$ & $-49.90(I .4 I)$ & $-46.56(3.52)$ & $-40.90(2.09)$ \\
\hline $\mathrm{dH}$ & $-113.26(17.58)$ & $-96.08(14.75)$ & $-180.43(19.70)$ & $-167.67(11.43)$ & $-144.22(16.74)$ & $-135.56(14.30$ \\
\hline TdS & $-44.97(6.64)$ & $-44.5 \mathrm{I}(9.27)$ & $-59.86(19.96)$ & $-60.74(8.13)$ & $-49.93(5.65)$ & $-49.37(7.43)$ \\
\hline$d G$ & -68.29 & -51.56 & -120.57 & -106.93 & -94.29 & -86.19 \\
\hline Number of $\mathrm{H}$-bonds & $9 / 9$ & $9 / 9$ & $13 / 13$ & $13 / 9$ & $23 / 18$ & $17 / 14$ \\
\hline
\end{tabular}

Notes: MM-PBSA estimates of free energies of binding (dG), together with all important energetic components and numbers of dendrimer/protein $\mathrm{H}$-bonds detected in final configurations (total number/number of $\mathrm{SO}_{3}$-protein $\mathrm{H}$-bonds; the rest are $\mathrm{C}_{2} \mathrm{~N}_{3}$ ring-protein $\mathrm{H}$-bonds). Numbers in brackets represent standard deviation. Units are $\mathrm{kcal} / \mathrm{mol}$ unless otherwise indicated.

Abbreviations: MM-PBSA, molecular mechanics energies combined with the Poisson-Boltzmann and surface area continuum solvation; VDW, van der Waals; EEL, electrostatic contribution in vacuum; ENPOLAR, estimate for non-polar contribution; EPB, energetic contribution arising from electrostatic solvent-solute interaction; $\mathrm{dH}$, total enthalpic contribution to free binding energy; $\mathrm{dS}$, solute entropy change due to binding; $\mathrm{T}$; absolute temperature.

cells, whereas reporter TZM.bl cells were used as target cells (Figure 5). In total, $91 \%$ and $92 \%$ reduction of viral transmission, measured as luciferase expression in target cells, was observed when TZM.bl were pretreated for 1 hour with G3-S16 or G2-NF16, respectively, and then cocultured with X4-HIV-1 ${ }_{\mathrm{NL} 4.3}$-infected Raji-DC-SIGN (Figure 5A). In case of R5 infection, an HIV-1 transmission reduction of $66 \%$ and $83 \%$ was found whether target cells were pretreated with G3-S16 and G2-NF16, respectively.

Since DCs are proposed as one of the first cells that encounter HIV-1 during sexual transmission and they mediate the spread of HIV-1 to CD4+ T-cells in lymphoid tissues, we also studied if dendrimers can impede cell-to-cell HIV-1 transmission using primary Mo-dDCs as donor cells (Figure 5B). When TZM.bl target cells were treated with dendrimer and then cocultured with infected DCs, $89 \%$ and $50 \%$ reduction (for X4- and R5-HIV-1-infected DCs, respectively) was observed for G3-S16 treatment and a decrease of $92 \%$ and $73 \%$ in HIV-1 transmission was found for G2-NF16 (Figure 5B). Colchicine that inhibits microtubule polymerization by binding to tubulin was used as a positive control for HIV-1 transmission inhibition since microtubule polymerization is essential for the formation of synapse. Summing up, both carbosilane dendrimers impeded cell-to-cell HIV transmission when we used Raji-DC-SIGN or primary DCs as infected donor cells. In addition, the reduction in HIV-1 transmission was more effective for X4-HIV-1 ${ }_{\mathrm{NL} 4.3}$ than R5-HIV-1 $1_{\mathrm{NL}(\mathrm{AD} 8)}$ isolate.

\section{Effect of dendrimers in infectious synapse formation}

HIV-1 cell-to-cell transmission is more efficient to infect new cells than cell-free virus. This is essentially due to the formation of virological synapse between infected cells and

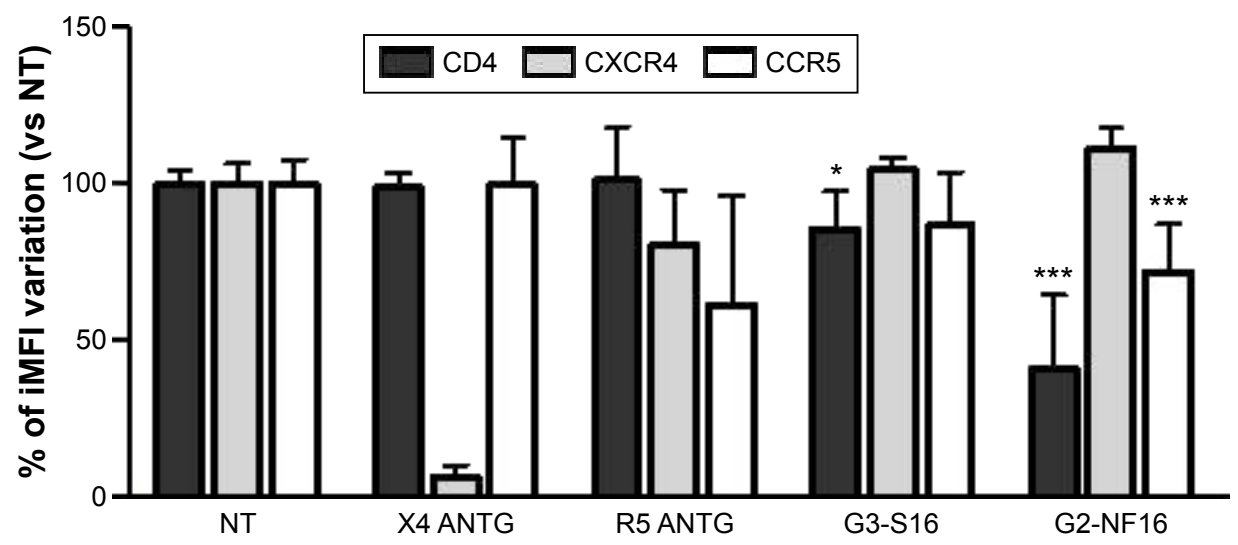

Figure 4 Interaction of G3-SI6 and G2-NFI 6 with cellular surface markers.

Notes: Activated PBMCs were treated with dendrimers, and levels of CD4, CXCR4, and CCR5 at the cellular surface were followed by flow cytometry. Ratio of iMFI for each surface marker in comparison to nontreated cells is shown (iMFI $=\%$ of positive cells $\times$ MFI of surface marker). X4 ANTG = CXCR4 antagonist AMD3I00; R5 ANTG = CCR5 antagonist TAK779. Both compounds were used as controls $(* P<0.05$, $* * * P<0.001$ vs control). Data represent the mean \pm SD of three independent experiments. Abbreviations: PBMCs, perpipheral blood mononuclear cells; iMFI, integrated mean fluorescence intensity; SD, standard deviation; NT, nontreated. 

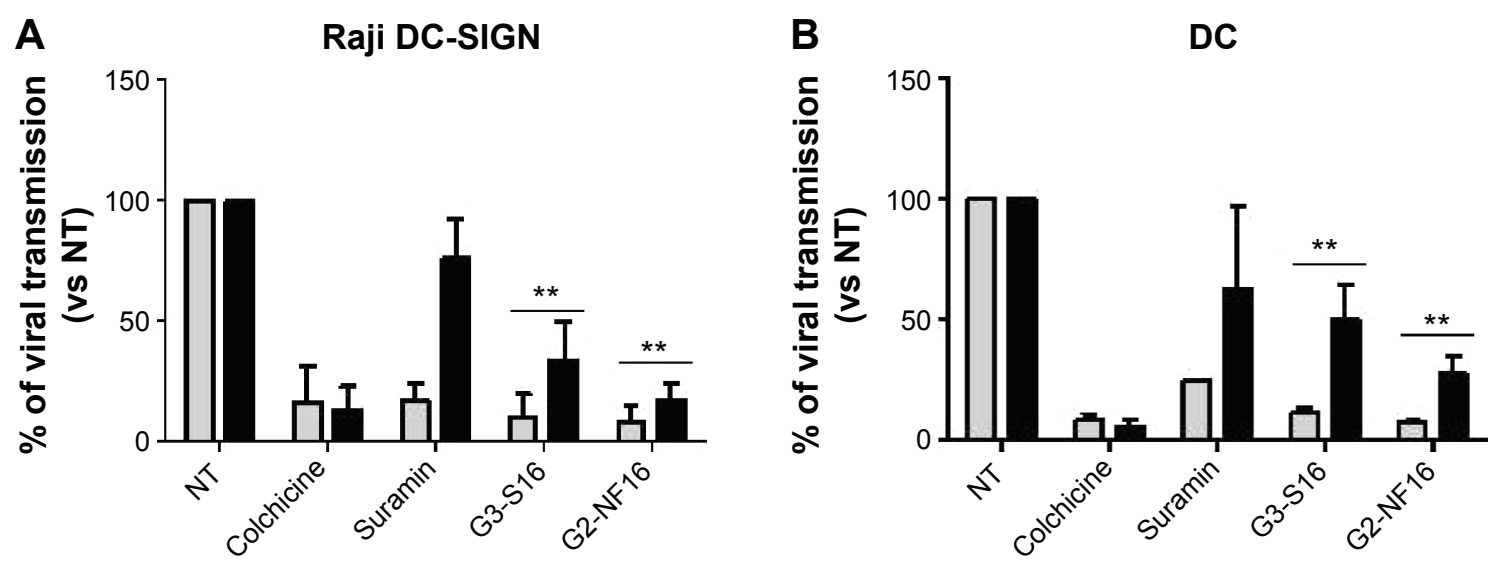

X4 HIV R5 HIV

Figure 5 Dendrimer activity in cell-to-cell HIV transmission.

Notes: Reduction in viral transmission after pretreatment of target cells when cocultured with X4 or R5-HIV-I-infected donor Raji-DC-SIGN (A) or human primary mature DCs (B). Viral transfer was determined by measuring luciferase expression levels in TZM.bl receptor cells. Colchicine and suramin were used as controls. Data represent the mean $\pm S D$ of three independent experiments $(* * P<0.0$ l vs control).

Abbreviations: DC, dentritic cell; SD, standard deviation; NT, nontreated; HIV, human immunodeficiency virus.

noninfected cells where virus could be found. To determine the role of dendrimers in cell-to-cell HIV transmission inhibition, confocal microscopy of HIV transinfection from donor DCs to Jurkat target cells was done (Figure 6). When cells were not treated, virus was clearly detected at the contact between DCs and Jurkat in cell conjugates. Moreover, virus was found colocalized with CD81 markers as previously described. ${ }^{47}$ Dendrimers impeded partially the formation of infectious synapse (Figure 6A, B, E, and F). Approximately $50 \%$ of reduction in the number of infectious synapses was observed when donor cells and receptor cells were treated with G3-S16 and G2-NF16 or with the control compound colchicine (Figure 6E).

Moreover, we studied the distribution of HIV-1 particles inside DCs during transinfection process when these cells or target cells were treated with compounds. In control HIV-1-challenged mature DCs, around half of total cells contained the virus in an intracellular sac-like compartment containing CD81 as described. ${ }^{47,48}$ However, differences in HIV distribution were found when donor or receptor cells were treated and cocultured. When cells were treated with colchicine, the majority of DCs contained the virus in this intracellular compartment ( $73 \%$ and $56 \%$ when treating target or donor cells, respectively). Nevertheless, HIV-1 was found in a diffuse distribution inside cytoplasm (as detected in nontreated DC alone) in a sac-like compartment (Figure 6B-F), and colocalization between HIV-1 and CD81 was partially lost when cells were treated with dendrimers (Figure 6B and C). The majority of DCs contained the HIV-1 in a diffuse distribution in the cytoplasm or under the membrane when donor DCs were treated ( $66 \%$ and $72 \%$ for G3-S16 or G2-NF16 treatment, respectively). On the other hand, when we treated Jurkat target cells, an increase of HIV-1 in the sac-like intracellular compartment was observed in DCs in comparison with NT donor DCs ( $26 \%$ and $40 \%$ for G3-S16 and G2-NF16 when treated Jurkat cells vs $10 \%$ for NT DCs harboring HIV). Summing up, dendrimers treatment impedes the HIV cell-to-cell transmission by limiting the formation of viral synapse. Moreover, the loss for colocalization between HIV-1 and CD81 could suggest that a redistribution of HIV-1 is out of the sac-like compartment, as has been described in scientific literature.

\section{Discussion}

In our work, we explain the mechanism of polyanionic carbosilane dendrimers G3-S16 and G2-NF16 inhibiting HIV-1 infection. We demonstrated that they inhibited HIV-1 infection at the fusion and the entry step. Carbosilane dendrimers impeded the binding of viral particles to target cell surface and membrane fusion, through the blockage of the gp120-CD4 interaction. Moreover, they blocked HIV-1 entry in epithelial cells (as previously published). ${ }^{24}$

G3-S16 and G2-NF16 are polyanionic compounds, and their mechanism is associated with electrostatic interactions between their different periphery functional groups and proteins of the HIV-1 envelope such as gp 120 , which ultimately prevents binding of the virus to the target cells. However, we demonstrated that dendrimers can also bind with several proteins at the cell surface that were related to the HIV-1 infection process such as $\mathrm{CD} 4$ or CCR5 coreceptor. No binding 


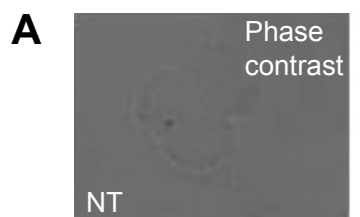

B

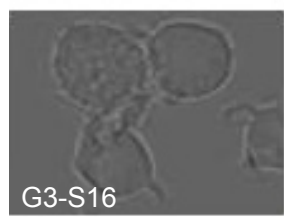

C

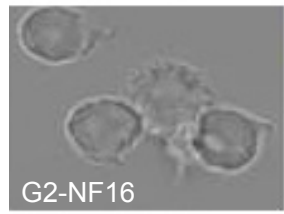

D

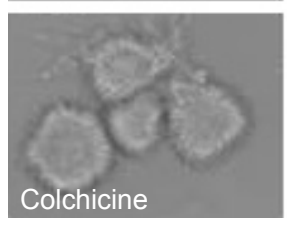

E
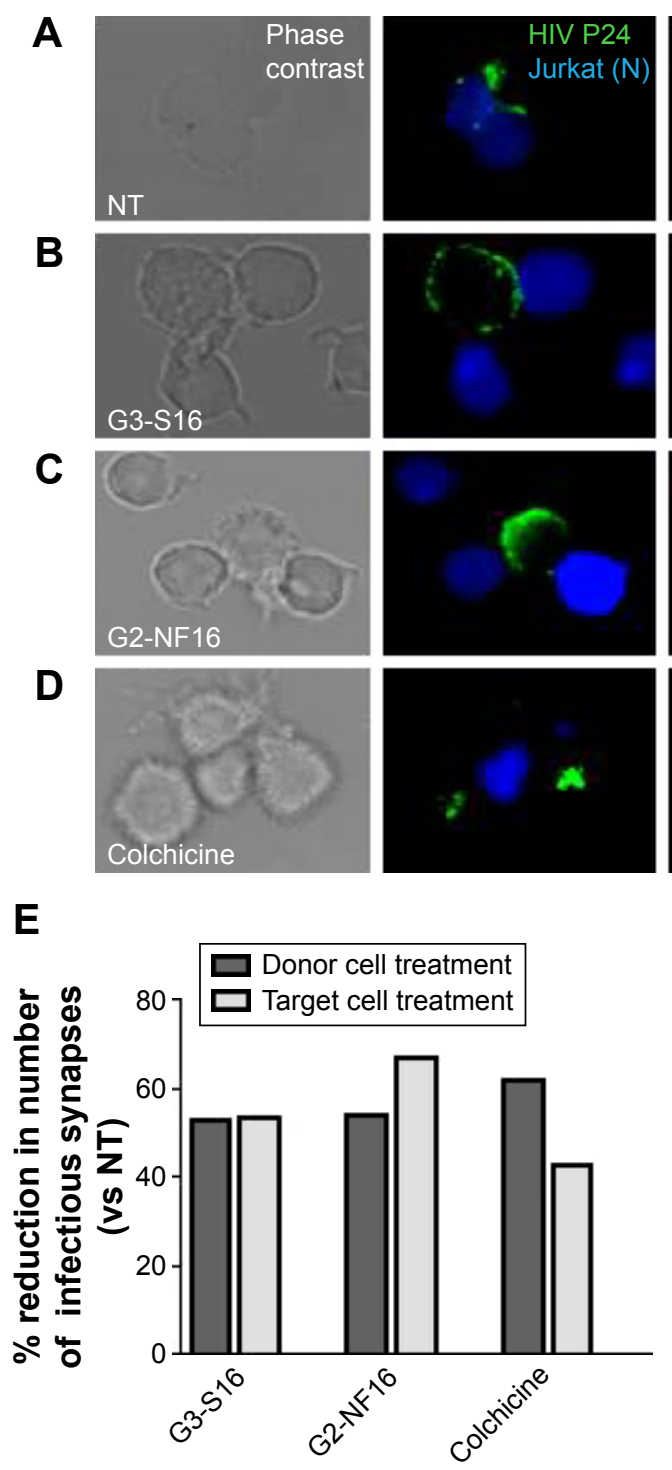
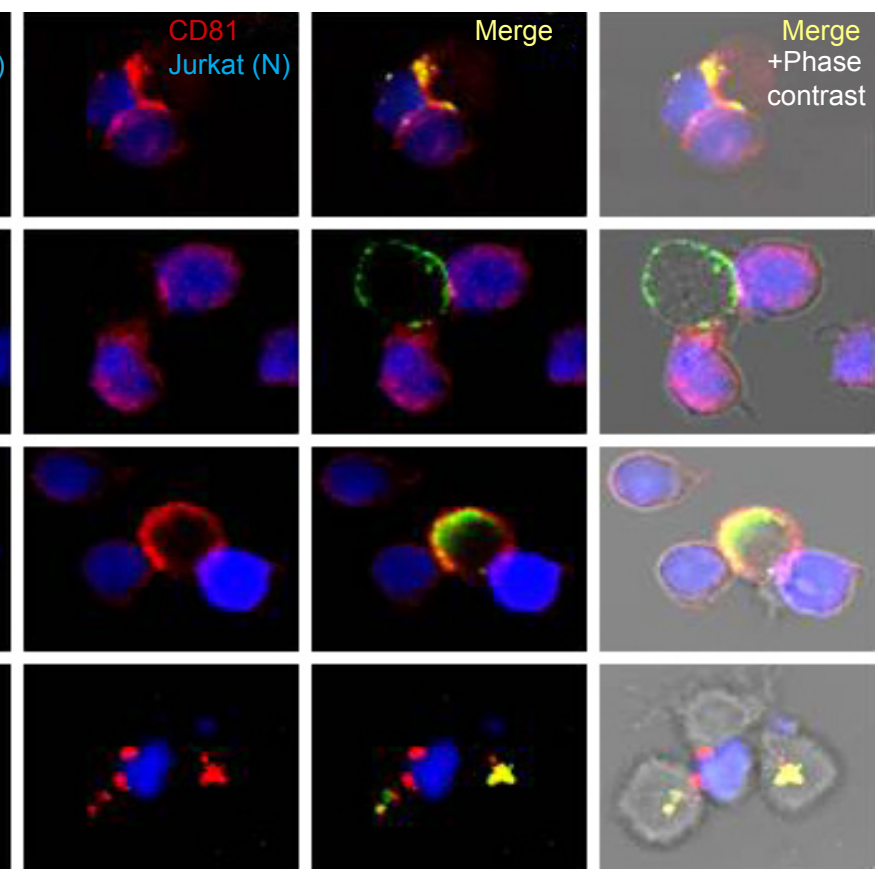

F $\quad$ Intracellular compartment

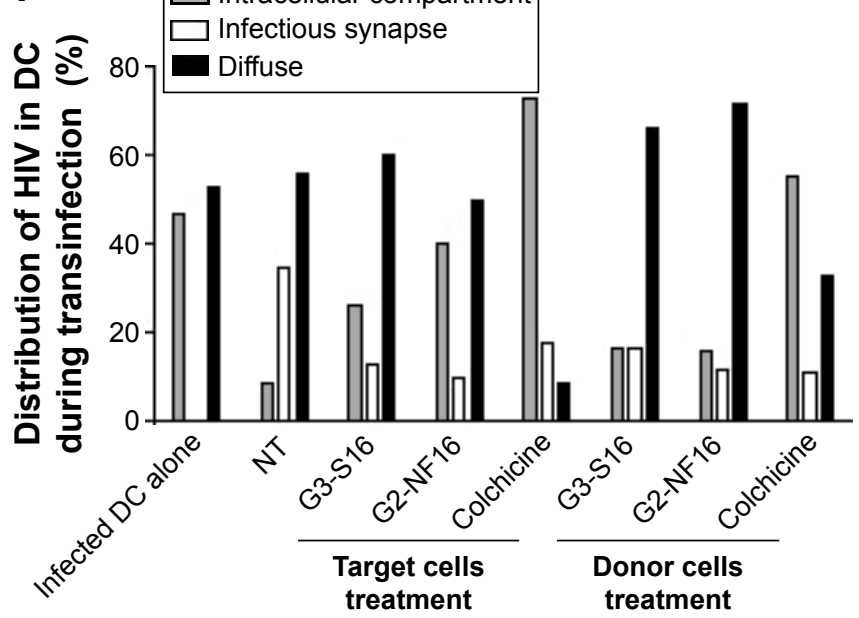

Figure 6 Effect of carbosilane dendrimers in infectious synapse.

Notes: Confocal microscopy images of DC-Jurkat cells contacts in absence (A) or presence of G3-SI6 (B), G2-NFI6 (C), or colchicine (D). Jurkat cells were stained in blue (CFSE-violet), HIV P24 was labeled in green, and CD8I marker was labeled in red. The number of total contacts between DCs and receptor Jurkat cells was counted, and $\%$ of infectious synapses was quantified. We defined an infectious synapse as a DC-Jurkat conjugate where the majority of HIV was focused at the zone of contact between both cells. Percentage of reduction in the number of infectious synapses with respect to NT cells is shown (E). Virological infectious synapses were counted when DC donor cells and receptor cells were treated with dendrimers. The distribution of HIV particles inside DCs during transinfection process was also analyzed and quantified (F). Fluorescence images showed different patterns of HIV distribution in DC-Jurkat conjugates: infectious synapse, intracellular compartment, or diffuse distribution of HIV particles inside cytoplasm or at the membrane. Events from two independent experiments were counted images were taken at $63 \times$ using a $63 \times$ PL-APO NA I.3 glycerol immersion objective of an inverted confocal fluorescence microscope (SP2; Leica Microsystems, Heidelberg, Germany).

Abbreviations: DC, dentritic cell; HIV, human immunodeficiency virus; NT, nontreated; CFSE, carboxyfluorescein succinimidyl ester.

of dendrimers to CXCR4 coreceptor was found. However, a preferential inhibition of X4-HIV strains by carbosilane dendrimers has been demonstrated. To explain this fact, it could be interesting to evaluate the ability of dendrimers to interact with gp120 from different X4-HIV isolates by using molecular modeling. A preferential attachment of dendrimers to X4-tropic gp120 proteins instead of R5-gp120 could clarify this point. Future work would be needed to confirm this hypothesis.
In addition, and for the first time, we demonstrated that dendrimers inhibit cell-to-cell HIV-1 transmission and difficult infectious synapse formation. Using neutralizing antibodies against gp120 and gp41, Massanella et $\mathrm{al}^{49}$ showed that anti-gp120 but not anti-gp41 antibodies block infectious cell-to-cell HIV-1 transmission. Thus, the ability of dendrimers to bind gp 120 could permit the loss of union between gp120 with other cell proteins pivotal in the infectious synapse formation. Nevertheless, due to their charged 
character, we cannot rule out that dendrimers might bind unspecifically to several molecules involved in infectious synapse formation such as siglec-1, ICAM-1, or LFA-1. ${ }^{50-52}$ More experiments should be done in the future to research this point. We also found differences when studying the distribution of HIV-1 particles inside DCs during a transinfection process. In case of donor DC treatment, the majority of DCs contained the HIV-1 diffused inside the cytoplasm, whereas an increase of DCs containing the HIV-1 in the intracellular sac-like compartment was observed when receptor cells were treated. We hypothesize that it may be related with a differential inhibitory mechanism of dendrimers in each case. When HIV-1 harboring DCs were treated, dendrimers could impede HIV-1 particles to surf to the polarized region of the cell or to the already described intracellular compartment, showing a diffuse distribution. The default in HIV-1 intracellular localization could impede the formation of the virological synapse. However, when we treated receptor cells, HIV-1 is mainly grouped in the intracellular sac-like compartment of HIV-challenged DCs, but viral particles cannot be recruited at the infectious synapse region. In this case, we could assume that dendrimers would be preventing the specific protein interactions at the cell-to-cell contact area and thus block the right signaling pathways for synapse formation.

Finally, because dendrimers play a role at the first step of HIV-1 infection in a multifunctional manner, their combination with other anti-HIV-1 drugs acting at different steps of viral cycle such as retrotranscriptase or integrase inhibitors could be interesting to generate new potent combinatorial microbicides. ${ }^{29,53,54}$

\section{Acknowledgments}

We acknowledge the Center of Transfusion of Madrid for the buffy coats and the Spanish HIV HGM BioBank for their process. We thank Rafael Samaniego and Laura Díaz from confocal microscopy and cytometry analysis units of HGUGM, respectively. This work has been (partially) funded by the RD12/0017/0037 project as part of Acción Estratégica en Salud, Plan Nacional de Investigación Científica, Desarrollo e Innovación Tecnológica 2008-2011 and cofinanced by Instituto de Salud Carlos III (ISCIII) (Subdirección General de Evaluación) and Fondo Europeo de Desarrollo Regional. RETIC PT13/0010/0028, El Fondo de Investigación Sanitaria (grant number PI13/02016), CTQ2011-23245 and CTQ201454004-P (MIMECO), Comunidad de Madrid (grant numbers S-2010/BMD-2351 and S-2010/BMD-2332), CYTED 214RT0482. CIBER-BBN is an initiative funded by the VI National R\&D\&i Plan 2008-2011, Iniciativa Ingenio 2010, the Consolider Program, and CIBER Actions and financed by the ISCIII with assistance from the European Regional Development Fund. This work was supported partially by a Marie Curie International Research Staff Exchange Scheme Fellowship within the 7th European Community Framework Programme, project number PIRSES-GA-2012-316730 NANOGENE, cofinanced by the Polish Ministry of Science and Higher Education (grant number W21/7PR/2013). MP is supported by Spanish MICINN through the Ramón y Cajal (RYC-2009-05486) and by Fondos de Investigación Sanitaria ISCIII (PI12_01763).

\section{Author contributions}

EV-C, MP, and M ÁM-F designed, performed experiments, and composed the figures. MM performed the computational work for molecular modeling. FJM and RG synthetized the dendrimers. All authors contributed toward data analysis, drafting, and critically revising the paper and agree to be accountable for all aspects of the work.

\section{Disclosure}

The authors report no conflicts of interest in this work.

\section{References}

1. (UNAIDS) JUNPoHA. UNAIDS Report on the Global AIDS Epidemic. (UNAIDS) JUNPoHA; 2014. Available from: http://www.unaids.org/ sites/default/files/media_asset/GARPR_2014_guidelines_en_0.pdf. Accessed January 21, 2016.

2. (UNAIDS) JUNPoHA. UNAIDS 2011-2015 STRATEGY: Getting to Zero. (UNAIDS) JUNPoHA; 2010. Available from: http:// www.unaids.org/sites/default/files/sub_landing/files/JC2034_ UNAIDS_Strategy_en.pdf

3. Abdool Karim SS, Baxter C. Microbicides \& their implications in HIV prevention. Indian J Med Res. 2010;132(6):656-659.

4. Anton PA. Future prospects and perspectives on microbicides. Curr HIV Res. 2012;10(1):113-115.

5. Buckheit RW Jr, Watson KM, Morrow KM, Ham AS. Development of topical microbicides to prevent the sexual transmission of HIV. Antiviral Res. 2010;85(1):142-158.

6. Quinones-Mateu ME, Vanham G. HIV microbicides: where are we now? Curr HIV Res. 2012;10(1):1-2.

7. Abdool Karim Q, Abdool Karim SS, Frohlich JA, et al. Effectiveness and safety of tenofovir gel, an antiretroviral microbicide, for the prevention of HIV infection in women. Science. 2010;329(5996):1168-1174.

8. Gibson RM, Arts EJ. Past, present, and future of entry inhibitors as HIV microbicides. Curr HIV Res. 2012;10(1):19-26.

9. Pirrone V, Wigdahl B, Krebs FC. The rise and fall of polyanionic inhibitors of the human immunodeficiency virus type 1. Antiviral Res. 2011;90(3):168-182.

10. Van Damme L, Govinden R, Mirembe FM, et al. Lack of effectiveness of cellulose sulfate gel for the prevention of vaginal HIV transmission. N Engl J Med. 2008;359(5):463-472.

11. Bourne N, Stanberry LR, Kern ER, Holan G, Matthews B, Bernstein DI. Dendrimers, a new class of candidate topical microbicides with activity against herpes simplex virus infection. Antimicrob Agents Chemother. 2000;44(9):2471-2474.

12. Chonco L, Pion M, Vacas E, et al. Carbosilane dendrimer nanotechnology outlines of the broad HIV blocker profile. J Control Release. 2012;161(3):949-958 
13. Jimenez J, Pion M, De la Mata FJ, et al. Dendrimers as topical microbicides with activity against HIV. New J Chem. 2012;36:299-309.

14. Kim BY, Rutka JT, Chan WC. Nanomedicine. N Engl J Med. 2010; 363(25):2434-2443.

15. Klajnert B, Bryszewska M. Dendrimers: properties and applications. Acta Biochim Pol. 2001;48(1):199-208.

16. Mallipeddi R, Rohan LC. Progress in antiretroviral drug delivery using nanotechnology. Int J Nanomedicine. 2010;5:533-547.

17. Weber N, Ortega P, Clemente MI, et al. Characterization of carbosilane dendrimers as effective carriers of siRNA to HIV-infected lymphocytes. J Control Release. 2008;132(1):55-64.

18. Tyssen D, Henderson SA, Johnson A, et al. Structure activity relationship of dendrimer microbicides with dual action antiviral activity. PLoS One. 2010;5(8):e12309.

19. Telwatte S, Moore K, Johnson A, et al. Virucidal activity of the dendrimer microbicide SPL7013 against HIV-1. Antiviral Res. 2011;90(3): 195-199.

20. Asaftei S, Huskens D, Schols D. HIV-1 X4 activities of polycationic "viologen" based dendrimers by interaction with the chemokine receptor CXCR4: study of structure-activity relationship. J Med Chem. 2012;55(23):10405-10413.

21. Witvrouw M, Fikkert V, Pluymers W, et al. Polyanionic (ie, polysulfonate) dendrimers can inhibit the replication of human immunodeficiency virus by interfering with both virus adsorption and later steps (reverse transcriptase/integrase) in the virus replicative cycle. Mol Pharmacol. 2000;58(5):1100-1108.

22. Rosa Borges A, Wieczorek L, Johnson B, et al. Multivalent dendrimeric compounds containing carbohydrates expressed on immune cells inhibit infection by primary isolates of HIV-1. Virology. 2010; 408(1):80-88.

23. Garcia-Vallejo JJ, Koning N, Ambrosini M, et al. Glycodendrimers prevent HIV transmission via DC-SIGN on dendritic cells. Int Immunol. 2013;25(4):221-233.

24. Cordoba EV, Arnaiz E, Relloso M, et al. Development of sulphated and naphthylsulfonated carbosilane dendrimers as topical microbicides to prevent HIV-1 sexual transmission. AIDS. 2013;27(8):1219-1229.

25. Galan M, Sanchez-Rodriguez J, Cangiotti M, et al. Antiviral properties against HIV of water soluble copper carbosilane dendrimers and their EPR characterization. Curr Med Chem. 2012;19(29):4984-4994.

26. Ortega P, Copa-Patino JL, Munoz-Fernandez MA, Soliveri J, Gomez R, de la Mata FJ. Amine and ammonium functionalization of chloromethylsilane-ended dendrimers. Antimicrobial activity studies. Org Biomol Chem. 2008;6(18):3264-3269.

27. Ortega P, Macarena Cobaleda B, Hernandez-Ros JM, et al. Hyperbranched polymers versus dendrimers containing a carbosilane framework and terminal ammonium groups as antimicrobial agents. Org Biomol Chem. 2011;9(14):5238-5248.

28. Rasines B, Sanchez-Nieves J, Maiolo M, et al. Synthesis, structure and molecular modelling of anionic carbosilane dendrimers. Dalton Trans. 2012;41(41):12733-12748

29. Sepulveda-Crespo D, Lorente R, Leal M, et al. Synergistic activity profile of carbosilane dendrimer G2-STE16 in combination with other dendrimers and antiretrovirals as topical anti-HIV-1 microbicide. Nanomedicine. 2014;10(3):609-618.

30. Garcia-Merino I, de Las Cuevas N, Jimenez JL, et al. The Spanish HIV BioBank: a model of cooperative HIV research. Retrovirology. 2009;6:27.

31. Wu L, Martin TD, Carrington M, KewalRamani VN. Raji B cells, misidentified as THP-1 cells, stimulate DC-SIGN-mediated HIV transmission. Virology. 2004;318(1):17-23.

32. Folks TM, Powell D, Lightfoote M, et al. Biological and biochemical characterization of a cloned Leu-3-cell surviving infection with the acquired immune deficiency syndrome retrovirus. J Exp Med. 1986; 164(1):280-290.

33. Pion M, Stalder R, Correa R, Mangeat B, Towers GJ, Piguet V. Identification of an arsenic-sensitive block to primate lentiviral infection of human dendritic cells. $J$ Virol. 2007;81(21):12086-12090.
34. Arnáiz E, Vacas-Córdoba E, Galán M, et al. Synthesis of anionic carbosilane dendrimers via "click chemistry" and their antiviral properties against HIV. J Polym Sci A Polym Chem. 2014;52:1099-1112.

35. Furukawa H, Momota K, Agatsuma T, Yamamoto I, Kimura S, Shimada K. Mechanism of inhibition of HIV-1 infection in vitro by guanine-rich oligonucleotides modified at the $5^{\prime}$ terminal by dimethoxytrityl residue. Nucleic Acids Res. 1994;22(25):5621-5627.

36. Bayly CI, Cieplak P, Cornell W, Kollman PA. A well-behaved electrostatic potential based method using charge restraints for deriving atomic charges: the RESP model. J Phys Chem. 1993;97(40):10269-10280.

37. Gordon MS, Schmidt MW, editors. Advances in Electronic Structure Theory: GAMESS a Decade Later in Theory and Applications of Computational Chemistry: The First Forty Years. Amsterdam: Elsevier; 2005.

38. Wang J, Wolf RM, Caldwell JW, Kollman PA, Case DA. Development and testing of a general amber force field. J Comput Chem. 2004;25(9): $1157-1174$

39. Case DA, Darden TA, Cheatham TE, et al, editors. AMBER 12. San Francisco, CA: University of California; 2012.

40. Jenn-Huei Lii A, Norman A, Allinger L. The MM3 force field for amides, polypeptides and proteins. J Comput Chem. 1991;12(2):186-199.

41. Huang CC, Tang M, Zhang MY, et al. Structure of a V3-containing HIV-1 gp120 core. Science. 2005;310(5750):1025-1028.

42. Anandakrishnan R, Aguilar B, Onufriev AV. H++ 3.0: automating pK prediction and the preparation of biomolecular structures for atomistic molecular modeling and simulations. Nucleic Acids Res. 2012;40(Web Server issue):W537-W541.

43. Pettersen EF, Goddard TD, Huang CC, et al. UCSF chimera - a visualization system for exploratory research and analysis. J Comput Chem. 2004;25(13):1605-1612.

44. Gotz AW, Williamson MJ, Xu D, Poole D, Le Grand S, Walker RC. Routine microsecond molecular dynamics simulations with AMBER on GPUs. 1. generalized born. $J$ Chem Theory Comput. 2012;8(5): 1542-1555.

45. Miller BR, McGee TD, Swails JM, Homeyer N, Gohlke H, Roitberg AE. MMPBSA.py: an efficient program for end-state free energy calculations. J Chem Theory Comput. 2012;8(9):3314-3321.

46. Baker NA, Sept D, Joseph S, Holst MJ, McCammon JA. Electrostatics of nanosystems: application to microtubules and the ribosome. Proc Natl Acad Sci U S A. 2001;98(18):10037-10041.

47. Garcia E, Pion M, Pelchen-Matthews A, et al. HIV-1 trafficking to the dendritic cell-T-cell infectious synapse uses a pathway of tetraspanin sorting to the immunological synapse. Traffic. 2005;6(6):488-501.

48. Yu HJ, Reuter MA, McDonald D. HIV traffics through a specialized, surface-accessible intracellular compartment during trans-infection of T cells by mature dendritic cells. PLoS Pathog. 2008;4(8):e1000134.

49. Massanella M, Puigdomenech I, Cabrera C, et al. Antigp41 antibodies fail to block early events of virological synapses but inhibit HIV spread between T cells. AIDS. 2009;23(2):183-188.

50. Rodriguez-Plata MT, Puigdomenech I, Izquierdo-Useros N, et al. The infectious synapse formed between mature dendritic cells and CD4+ T cells is independent of the presence of the HIV-1 envelope glycoprotein. Retrovirology. 2013;10:42.

51. Izquierdo-Useros N, Lorizate M, Puertas MC, et al. Siglec-1 is a novel dendritic cell receptor that mediates HIV-1 trans-infection through recognition of viral membrane gangliosides. PLoS Biol. 2012;10(12): e1001448.

52. Coleman CM, Gelais CS, Wu L. Cellular and viral mechanisms of HIV-1 transmission mediated by dendritic cells. Adv Exp Med Biol. 2013; 762:109-130.

53. Belec L, Jenabian MA, Charpentier C, Saidi H. Combinatorial prevention of HIV transmission in women: the case for a vaginal microbicide. Future Microbiol. 2011;6(7):731-737.

54. Cordoba EV, Arnaiz E, De La Mata FJ, et al. Synergistic activity of carbosilane dendrimers in combination with maraviroc against HIV in vitro. AIDS. 2013;27(13):2053-2058. 


\section{Supplementary materials}

A

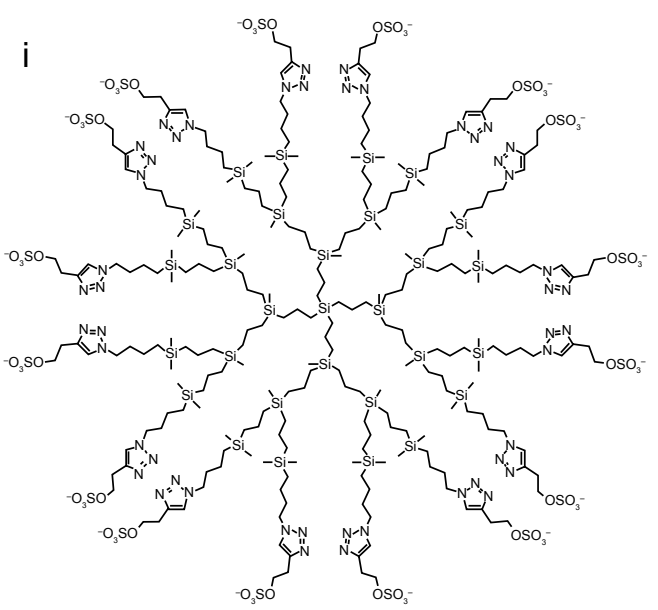

B

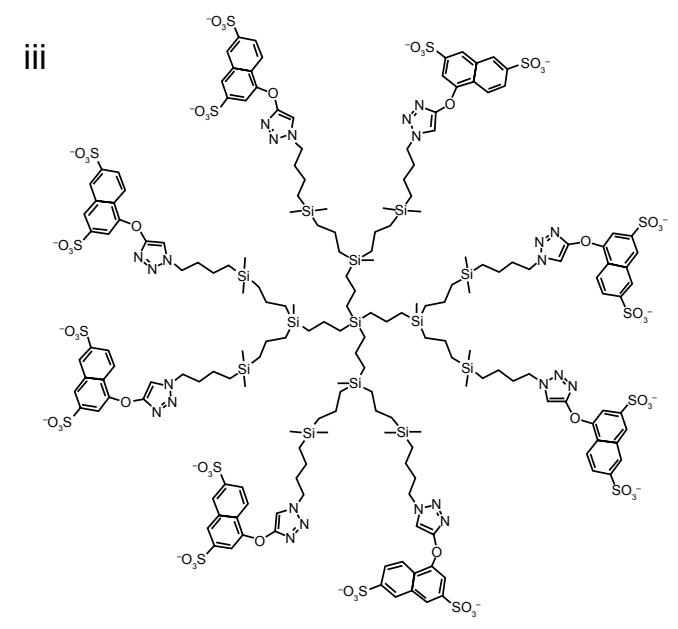

ii

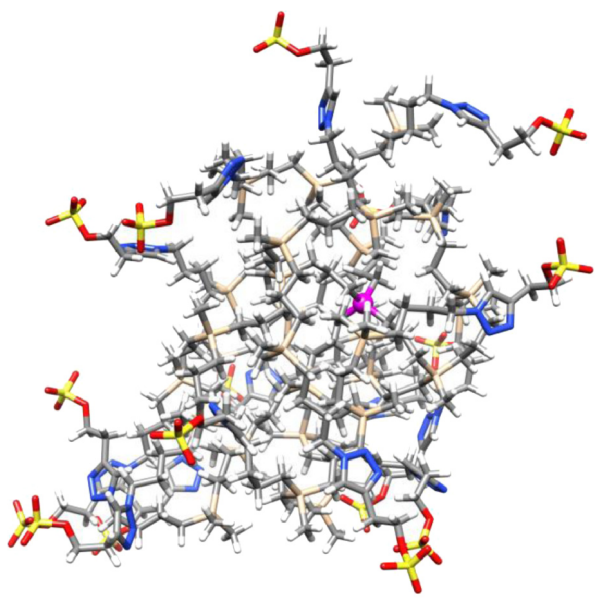

$20 \AA$

iv

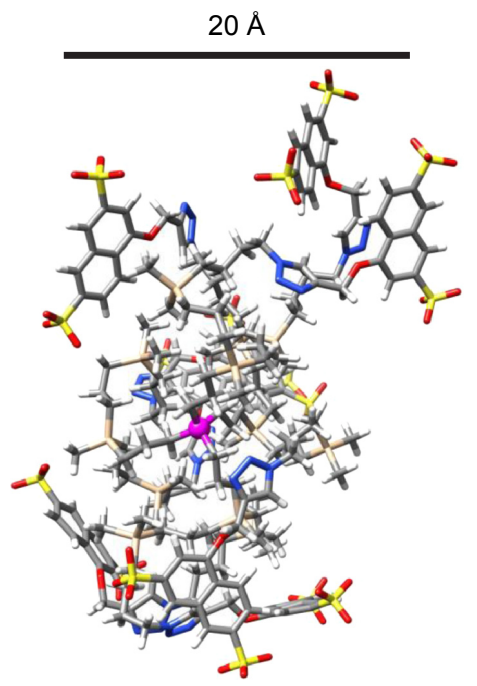

Figure SI Structure of polyanionic carbosilane dendrimers.

Notes: (A) (i) Third-generation G3-SI6, with 16 sulfated end groups. $\mathrm{C}_{256} \mathrm{H}_{508} \mathrm{~N}_{48} \mathrm{Na}_{16} \mathrm{O}_{64} \mathrm{~S}_{16} \mathrm{Si}_{29} ; \mathrm{MW}$ : 6,978.4I g/mol. (ii) Computer model of G3-SI6 equilibrated in salt water. (B) (iii) Second-generation G2-NFI6, with 16 naphthylsulfonated end groups. $\mathrm{C}_{184} \mathrm{H}_{244} \mathrm{~N}_{24} \mathrm{Na}_{16} \mathrm{O}_{56} \mathrm{~S}_{16} \mathrm{Si}_{13} ; \mathrm{MW}: 4,934.02 \mathrm{~g} / \mathrm{mol}$. (iv) Model of G2-NFI6 dendrimer equilibrated in salt water. The dendrimer Si core atom is colored in magenta. The color coding for all remaining atoms is $\mathrm{C}-$ gray, $\mathrm{O}-$ red, $\mathrm{Si}-$ beige, and $\mathrm{S}-\mathrm{yellow}$. Abbreviation: MW, molecular weight.

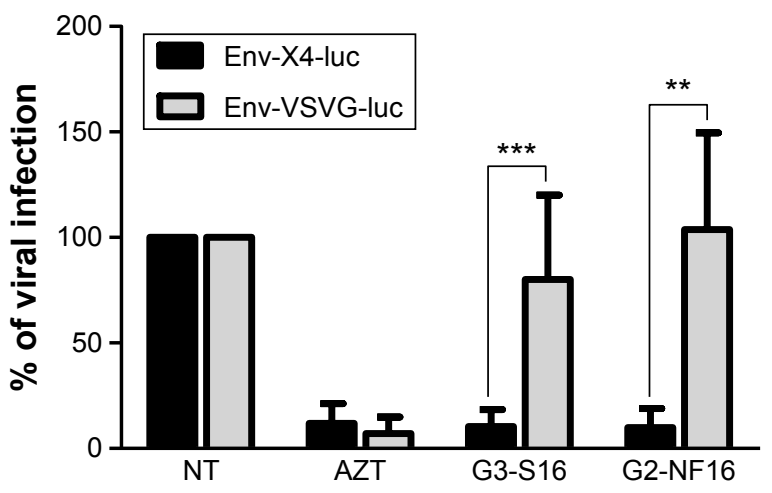

Figure S2 Specificity of antiviral activity.

Notes: Activated PBMCs were treated for I hour with nontoxic concentration of dendrimers and then infected overnight with env-X4-luc and env-VSVG-luc HIV-derived lentivirus. After 2 days of infection, viral infection was quantified measuring luciferase expression levels. AZT was used as positive control. (**P<0.0I, $* * * P<0.00 \mathrm{I}$ vs control). Data represent the mean \pm SD of three independent experiments.

Abbreviations: PBMCs, peripheral blood mononuclear cells; HIV, human immunodeficiency virus; SD, standard deviation; NT, nontreated; AZT, azidothymidine. 

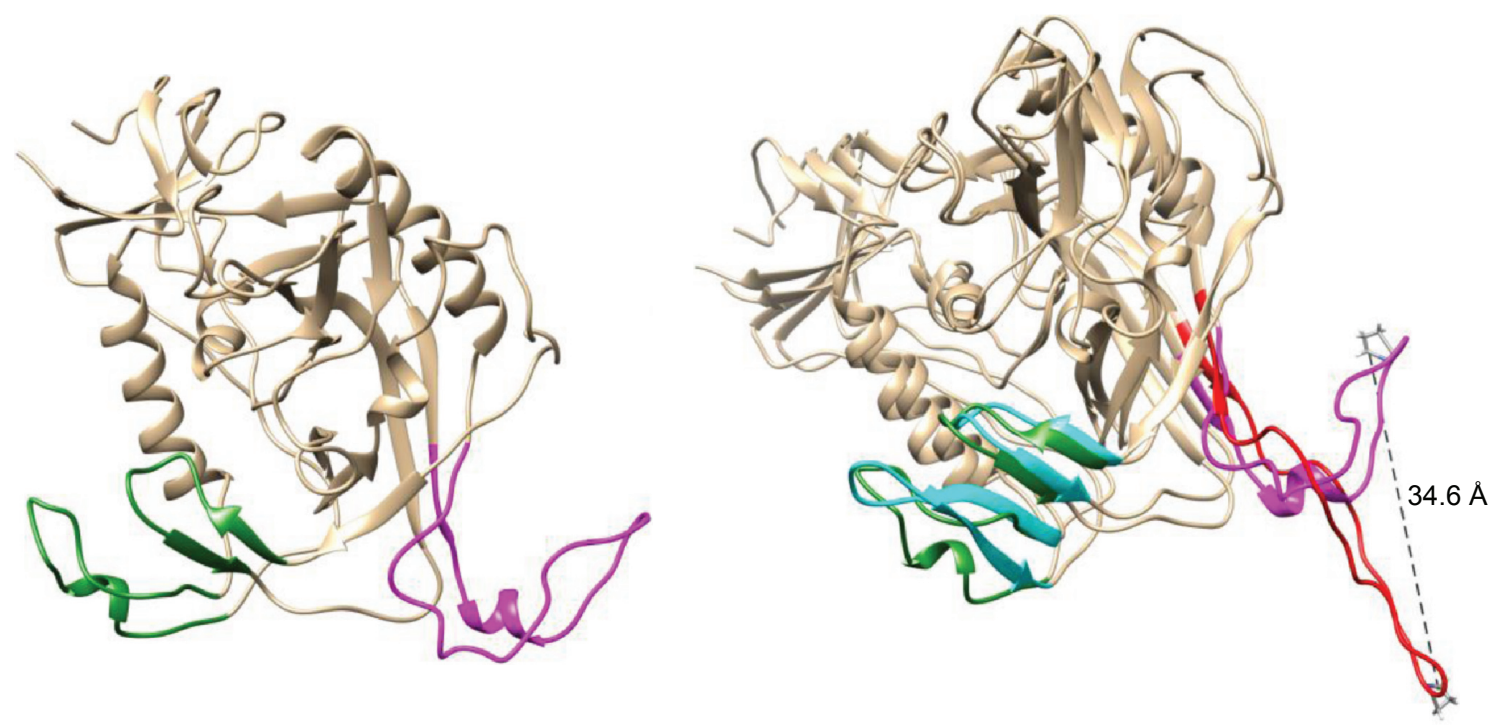

Figure S3 Equilibrated structure of gp I 20 after I00 ns of simulation (left) and superposition of this "unbound like" conformation with the original (bound) gp I 20 conformation (right).

Notes: Color coding: bridging sheet (terminal parts of VI/V2 loops) in green ("unbound like" configuration) and cyan (bound configuration) and V3 loop in magenta ("unbound like" configuration) and red (bound configuration).
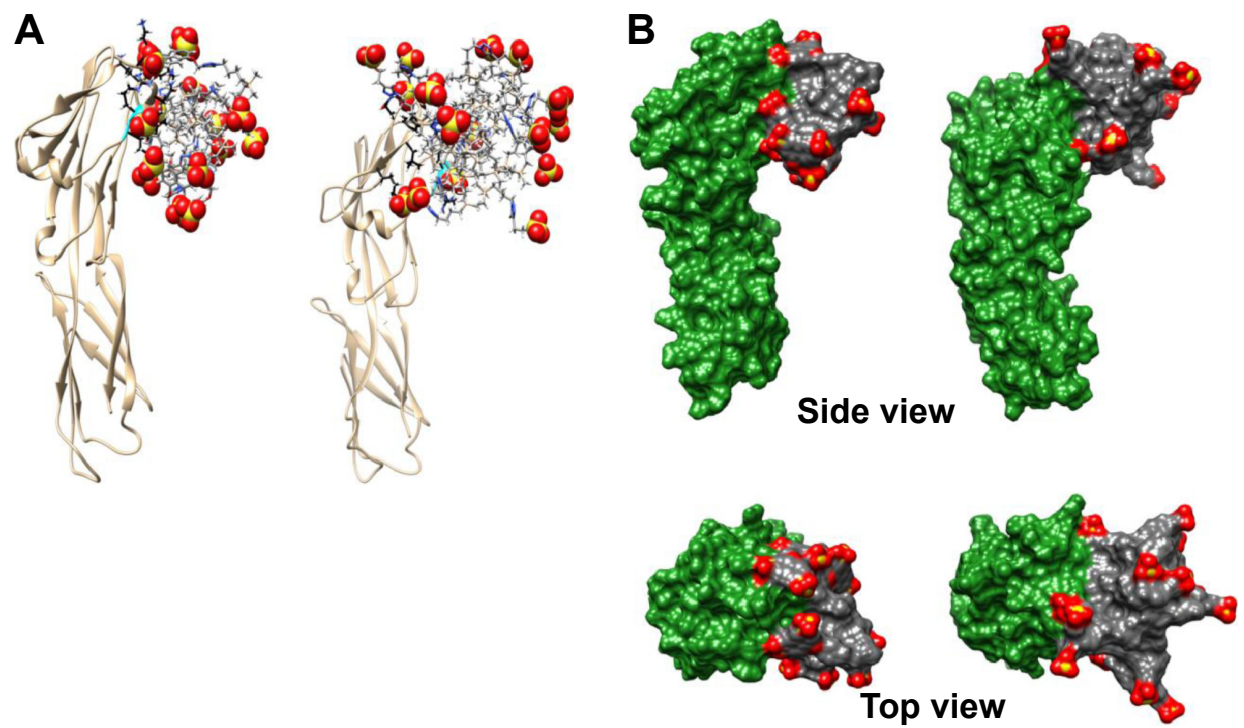

Figure S4 Molecular modeling of CD4-dendrimer complexes.

Notes: (A) CD4-G2-SI6 (left) and CD4-G3-S16 (right). Just the closest ( $\leq 3 \AA$ ) amino acids to the dendrimer are shown (in ball and stick) using black color for carbons to distinguish them from dendrimer carbons (in gray, stick representation). Colors of the other elements are $\mathrm{O}-$ red, $\mathrm{S}-\mathrm{yellow}, \mathrm{H}-\mathrm{white}$, and $\mathrm{Si}-$ tan. Part of the small alpha helix on CD4 colored in cyan localizes two neighboring arginines that contribute to cationic character of the surrounding area. This small helix is one of the important parts of the CD4-gPI 20 or CD4-anionic dendrimer binding interface. For the terminal SO 3 groups, the sphere representation is used. (B) CD4-G2-NFI6 (left) and CD4-G3-SI6 (right) complexes with visualized molecular surfaces to better see mutual dendrimer-protein integration. The CD4 molecular surface is in green and dendrimer molecular surface is in gray, except the terminal $\mathrm{SO}_{3}$ groups where red is used for oxygen and yellow for sulfur.

International Journal of Nanomedicine

\section{Dovepress}

\section{Publish your work in this journal}

The International Journal of Nanomedicine is an international, peerreviewed journal focusing on the application of nanotechnology in diagnostics, therapeutics, and drug delivery systems throughout the biomedical field. This journal is indexed on PubMed Central, MedLine, CAS, SciSearch ${ }^{\circledR}$, Current Contents ${ }^{\circledR} /$ Clinical Medicine,

Journal Citation Reports/Science Edition, EMBase, Scopus and the Elsevier Bibliographic databases. The manuscript management system is completely online and includes a very quick and fair peer-review system, which is all easy to use. Visit http://www.dovepress.com/ testimonials.php to read real quotes from published authors. 